\title{
Skillful coping with and through technologies
}

\section{Some challenges and avenues for a Dreyfus-inspired philosophy of technology}

\author{
Mark Coeckelbergh $^{1}$ (i)
}

Received: 22 May 2017 / Accepted: 24 January 2018 / Published online: 3 February 2018

(c) The Author(s) 2018. This article is an open access publication

\begin{abstract}
Dreyfus's work is widely known for its critique of artificial intelligence and still stands as an example of how to do excellent philosophical work that is at the same time relevant to contemporary technological and scientific developments. But for philosophers of technology, especially for those sympathetic to using Heidegger, Merleau-Ponty, and Wittgenstein as sources of inspiration, it has much more to offer. This paper outlines Dreyfus's account of skillful coping and critically evaluates its potential for thinking about technology. First, it is argued that his account of skillful coping can be developed into a general view about handling technology which gives due attention to know-how/implicit knowledge and embodiment. Then a number of outstanding challenges are identified that are difficult to cope with if one remains entirely within the world of Dreyfus's writings. They concern (1) questions regarding other conceptualizations of technology and human-technology relations, (2) issues concerning how to conceptualize the social and the relation between skill, meaning, and practices, and (3) the question about the ethical and political implications of his view, including how virtue and skill are related. Acknowledging some known discussions about Dreyfus's work, but also drawing on other material and on the author's previous writings, the paper suggests that to address these challenges and develop the account of skillful coping into a wider scoped, Dreyfusinspired philosophy of technology, it could take more distance from Heidegger's conceptions of technology and benefit from (more) engagement with work in postphenomenology (Ihde), pragmatism (Dewey), the later Wittgenstein, and virtue ethics.
\end{abstract}

Keywords Dreyfus $\cdot$ Skillful coping $\cdot$ Technology $\cdot$ The social $\cdot$ Virtue $\cdot$ Wittgenstein $\cdot$ Dewey

\section{Introduction}

For philosophers of technology, Dreyfus's work is an attractive and outstanding example of how one can combine philosophical thinking with a focus on specific technologies such as artificial intelligence (AI), and indeed how one can do excellent philosophy by thinking about technology. Compared to the often shallow contemporary debates about AI, robotics, or transhumanism, for example, Dreyfus's thinking is a relief. His philosophical arguments against the idea that AI can give us a human-like general intelligence are still highly relevant today, when absurd Platonic-Cartesian ideas such as mind uploading or projects trying to artificially

Mark Coeckelbergh

mark.coeckelbergh@univie.ac.at

1 University of Vienna, Universitätsstraße 7, 1010 Vienna, Austria recreate the human brain are gaining more traction than they deserve.

But there is more to Dreyfus's work than thinking about $\mathrm{AI}$, and there is much more to be gained from it for thinking about technology, especially for those philosophers sympathetic to using Heidegger, Merleau-Ponty, and Wittgenstein. This paper focuses on Dreyfus's account of skillful coping and critically evaluates its potential for thinking about technologies today. After sketching a brief working account of skillful coping and exploring what it means for thinking about technology, a number of challenges are identified and some avenues to cope with these challenges are opened uppartly by drawing on Dreyfus and partly by going against or beyond Dreyfus.

In particular, the paper identifies problems related to (1) Dreyfus's selection of tool use as the only way to conceptualize technology (and what Ihde calls the 'embodiment' relation as the only relevant human-technology relation), together with the unfortunate repetition of the (later) 
Heidegger's inconsistencies and bias regarding contemporary technologies; (2) his underdeveloped conceptualization of the social and of the relations between skill, meaning, and practice; and (3) the question regarding the ethical and political implications of his view, including the question how skill and virtue are related. In the course of the paper, there will be references to some known debates about Dreyfus's approach, which are often related to its Heideggerian dimension, such as his Heideggerian interpretation of ground and his conceptualization of the social in terms of 'das Man' (translated by Dreyfus as 'the Anyone'). But the paper will also introduce other material to the discussion about Dreyfus's work, such as Ihde and Dewey.

This will lead to opening up some avenues that are not (fully) present in Dreyfus's own writings. In response to the problems identified, the paper proposes some ways in which a Dreyfus-inspired phenomenology of technology use and skill can be constructed and elaborated, but also revised, to address or avoid the problems previously indicated. Conceptual tools offered include philosophical schools and traditions Dreyfus sympathized with, but-focusing mainly on Heidegger and Merleau-Ponty—never (fully) used: postphenomenology, Dewey, the later Wittgenstein, and the tradition of virtue ethics - the latter interpreted in a way that replaces the Platonic and Aristotelian obsession with theory with the love of practical wisdom and know-how and an emphasis on the exercise of skill. In the course of the paper, some of these suggestions and new directions are supported by referring to the author's own work on skill and technology, which is inspired by Dreyfus's view but also critical of it.

In the conclusion, the suggestions and directions offered in the course of the paper are drawn together and presented as elements for a Dreyfus-inspired (but perhaps not Dreyfusian) research program in philosophy of technology. It is also stressed that the general direction Dreyfus took in his thinking on skill is not only important for philosophy of technology, but also stands as one of the conceptual building blocks all philosophers have at their disposal today to cope with a ghost that continues to haunt both philosophy and AI: the crazy idea that knowledge and thinking can be entirely formalized and divorced from lived experience and active coping in the world.

\section{Dreyfus's account of skillful coping and its implications for thinking about technology}

\subsection{Skillful coping}

Dreyfus's "skillful coping" view is based on his reading of the early Heidegger of Being and Time (1927), and has later found expression in the account of skill development, which he worked out with his brother Stuart Dreyfus (1980a), and in subsequent papers-some of which are bundled in the book Skillful Coping (2014)-that further elaborated this account and defended it against some objections. The main idea is that in practical activity and skillful coping, we do not rely on rules or mental representations, at least when we gain a sufficiently high degree of expertise and mastery.

In Being and Time (1927), Heidegger already made a distinction between two modes of experiencing a tool: when we use a tool, the tool withdraws, we do not notice it. It is ready-to-hand. Under other circumstances, for instance when something goes wrong, it might become present-athand. But the "default" mode, we may say, is ready-to-hand. For example, when I use my computer to write this paper, I do not notice the computer; but when the operating system crashes, the technology becomes present-at-hand. Moreover, in our skillful coping, we do not usually need mental representations. In Phenomenology of Perception (1962), Merleau-Ponty already emphasized embodiment and what Dreyfus interprets as a critique of mental representation (Dreyfus 2002a). He explains that Merleau-Ponty's terms 'the intentional arc' and 'getting a maximal grip' imply that skill, as a tight connection between the agent and the world, is not stored in the form of representations in the mind, but instead as an embodied tendency to respond (Dreyfus 2002a, 367); we are already set to respond, so to speak (373). Influenced by Heidegger and Merleau-Ponty, Dreyfus, in turn, argued that our knowledge of handling things involves a know-how that is not explicit. We are absorbed in what we do, perhaps even in a state of "flow", and we respond to the situation: 'According to Merleau-Ponty, in absorbed, skillful coping, I don't need a mental representation of my goal. Rather, acting is experienced as a steady flow of skillful activity in response to one's sense of the situation.' (Dreyfus 2002a, 378).

Against representationalism and Cartesianism in philosophy of mind and action, Dreyfus argued that the phenomenology of, and knowledge involved in, practical activity and skill acquisition is not based on rules or mental representations, but involves a coping that, especially when one is an expert, is based on implicit know-how and intuition. Our activity may be goal directed, but we do not think about the goal. Deliberation only comes in when coping is blocked (Dreyfus 2002a, 381), or indeed when we learn a new skill. We need rules when we are novices, but experts can do without them: rules are for beginners (Dreyfus and Dreyfus 1980a). As we move through stages of skill development, we rely on concrete experience rather than abstract principles. In the paper written with his brother Stuart they give the examples of language learning, chess playing, and flying an airplane, which entail performances and responses without the application of rules or principles: 'The expert pilot, having finally reached this 
non-analytical stage of performance, responds intuitively and appropriately to his current situation.' (Dreyfus and Dreyfus 1980,12). Moreover, experts can have the experience that they are intensely absorbed in what they do. Here there is no longer self-monitoring at all:

'masterful performance only takes place when the expert, who no longer needs principles, can cease to pay conscious attention to his performance and can let all the mental energy previously used in monitoring his performance go into producing almost instantaneously the appropriate perspective and its associated action.' (Dreyfus and Dreyfus 1980, 14).

Other terms that qualify this experience are 'holistic' and 'integrated'. Elsewhere Dreyfus argued that bodily skills such as swimming requires a kind of unification and integration, and cannot be reduced to rules and a sequences of movements learned by beginners:

'Even though bodily skills, for example, are sometimes learned by following rules which dictate a sequence of simple movements, when the performer becomes proficient the simple movements are left behind and a single unified, flexible, purposive pattern of behavior is all that remains. It makes no sense to attempt to capture a skill by using a representation of the original elements used by beginners, since these elements are not integrated into the final skill.' (Dreyfus 1980, 9).

In contrast to computers, which need to recognize an object to manipulate it, Dreyfus argued, humans do it in a more gestalt-like manner and instead can 'manipulate an object in order to recognize it'-in other words, they cope with the object (Dreyfus 1967, 21).

Against McDowell, Dreyfus argued that experience is not inherently conceptual and that we have to overcome the myth of the mental (Dreyfus 2005). While it is plausible that, as Rietveld has argued, both McDowell and Dreyfus share the view that our engagements with the world are situated and are each in their own way committed to phenomenologya view McDowell reached through Wittgenstein (Rietveld 2010, 185); Dreyfus mainly through Heidegger-Dreyfus did not share the former's strong emphasis on the rational and conceptual. Perception is not conceptual "all the way out", as McDowell agued; instead, Dreyfus focused on nonconceptual embodied coping (Dreyfus 2005, 47). Against cognitivism and against representing things from 'a detached theoretical perspective' (49), he argued that our everyday coping does not require our minds to impose meaning onto the world: 'We need to consider the possibility that embodied beings like us take as input energy from the physical universe and process it in such a way as to open them to a world organized in terms of their needs, interests, and bodily capacities without their minds needing to impose a meaning on a meaningless Given.' (Dreyfus 2005, 49). Instead, in our everyday coping, the world is already meaningful for us.

Moreover, whereas McDowell interprets Aristotle's account of practical wisdom (phronesis) in terms of responding to reasons, Dreyfus, using Heidegger, argued that practical wisdom is more like seeing what to do in a particular situation; it is about being 'responsive to the specific situation' (Dreyfus 2005, 51). Or more precisely: both thinkers share the interpretation of Aristotle's concept of practical wisdom in terms of responding to specific situations (Rietveld 2010, 189), but they have a different view of the role of reasons and concepts in this responding. According to McDowell, we respond to reasons and rationality 'permeates' even unreflective action (McDowell 2007, 368) and concepts are 'operative' in unreflective action (372); they show themselves in the activity. It is rationality in action (see also Rietveld 2010, 193). According to Dreyfus, by contrast, reasons are 'retroactive rationalizations' (Dreyfus 2005, 51) and unreflective action is not about rationality. Dreyfus repeated that when we learn a skill, we may use rules as a kind of aid first, but like the training wheels of children who learn to ride a bicycle, when we become experts we can leave them out and we switch to 'a more involved and situated way of coping.' (52).

Dreyfus's point was not that mental representation, goal directedness, reasons, etc. play no role at all in human experience; the point was that they do not usually play a role when we decide as experts; they may play a role at earlier stages (Dreyfus 2002b, 413). He thus stressed that some central cases of intelligent behavior-indeed most of our everyday coping-do not require mental representations (414). He rejected the view that we can only act if we have reasons to do so; reasons play no role and rather get in the way. Instead we have to sharpen our ability to make refined discriminations (Dreyfus 2005, 52). And of course a game has rules, but these rules are not stored in the mind or not even followed; instead, the expert copes and in her coping she is sensitive to the rules of the game (53). Everyday coping is intentional, but not conceptual. We respond to what Gibson called 'affordances', which happens without thinking at all (56). For example, doors afford going in and out, but we do not have to think about them-let alone calculate. When we learned a skill, we masterfully respond to specific situations. This gives us a familiarity with the world and openness to the world, which is not a totality of objects or of states of affairs. Instead we know how, and our skill opens a world. Our conceptual capacities grow 'out of our nonconceptual ones' (61).

In 'The Return of the Myth of the Mental' (Dreyfus 2007a), Dreyfus continued his arguments against McDowell, this time against the claim that in mature human beings, embodied coping is permeated with mindedness. Dreyfus stressed again the non-conceptual and non-mental 
content of skillful coping and performing. We can monitor our performances while performing, but this actually degrades the performance itself, especially since it disrupts the mindless absorbed coping. Of course we can step back and reflect, but also that kind of conceptual intentionality is based on a ground-floor of motor intentionality, and there is still involved coping going on in the background. Luckily we are only 'part-time rational animals' (Dreyfus 2007a, 354); we can exercise our freedom as humans not so much by thinking rationally, but rather by opening ourselves 'to being bound'-entering our involved coping (355). In this coping there is no thinking subject (358); rather, the world may afford or solicit:

'According to Merleau-Ponty, at the most basic level of being in the world, what does the grasping is not the mind but the body with its nonconceptual coping skills, and what is grasped are not unified, propositional structures that one can observe and entertain in thought, but more or less indeterminate solicitations to act.' (Dreyfus 2007a, 359).

To use one of Dreyfus's examples: when we take a doorknob to open the door, we do not think about this affordance or solicitation. We respond and do all this without thinking. Again, we can step back, but only against a pervasive background (363). Yet like in his previous paper on the topic, Dreyfus acknowledges that there is still an outstanding issue: we still want to know how the conceptual world is related to, or emerges from, the nonconceptual world (364). (I will return to this issue.)

Moreover, against Searle, Dreyfus argued that social meaning and norms are not representational (Dreyfus 1999) and do not require intentional action. According to Dreyfus, our experience of our everyday involvement conflicts with the logic of constitution and reconstruction proposed by Searle (Dreyfus 2001a, 181). The problem is not that analysts construct a rational account; we can do that. But it is wrong to suppose that we give meaning to artefacts. According to Dreyfus, following Heidegger and other existential phenomenologists, meaning must not be brought into a meaningless universe; there is already a meaningful world (Dreyfus 2001a, 186). We are 'from the start socialized into a world in which we cope with equipment' (187). For example, to use money (Searle's paradigmatic example), there is no need to think "this piece of paper counts as money"; we just use it and already see it as valuable if we grew up with it (189). There is already a meaningful world. There is already a cultural style, which we already pick up as a baby. There is already something binding on us, and we learn it without having to be conscious about the rules (195-196). Elsewhere Dreyfus wrote that there is a background to which we respond: a background of practices, which does not consist of representations at all (Dreyfus 1980b, 9). (I will soon say more about this.)

\subsection{Technology}

Whether or not Dreyfus's model of skill acquisition is a sound interpretation of Heidegger (for a discussion see Breivik 2007), it is an attractive model for understanding the everyday use and handling of technologies. Technology can be a tool we use, or (as we can add using postphenomenology — see the next section) it can be a medium through which we handle objects. In both cases, following Dreyfus we can say that skillful coping is involved-at least when we are expert users. There is no need to think about the technology; if we are experts there is even no need to think at all. We respond skillfully to the situation. Through technology the world offers affordances and solicitations, without any need for representation by means of concepts. Many examples Dreyfus uses are technological, such as using a doorknob or driving a car: the expert driver does not need to think about rules on how to shift the gears; if the driver is sufficiently skilled, there is a bodily response appropriate to the situation. Thus, apart from everything else it may be (e.g. a significant contribution to epistemology, philosophy of mind, etc.), Dreyfus's account of skillful coping is to be seen as a contribution to thinking about technology, to the extent that it enables us to say more about the kind of knowledge and experience involved in the use of everyday technologies such as hammers, cars, and doorknobs. It seems especially suitable to think about the handling of tools and equipment.

Sometimes Dreyfus explicitly addressed the question how we use tools. Drawing on Heidegger, Merleau-Ponty, and Polanyi, he argued that how we use a tool differs from explicit experience and representational knowledge of an object. Taking up Merleau-Ponty's example of the blind man's stick, he writes:

'A blind man who runs his hand along the stick he uses to grope his way will be aware of its objective characteristics. When he is using it, however, he is not aware of its objective traits nor of the pressure in the palm of his hand. Rather, the stick has become, like his body, a transparent access to objects.' (Dreyfus 1967, 27).

According to Dreyfus, this use has nothing to do with making calculations or with following rules or principles. It is an embodied kind of coping, a learning of skill: I first happen to touch something and then I repeat it, correct it, and so on. I consciously intervene to improve my performance. But there is not first a knowledge of rules. Whereas the skilled performance may be described (from the outside, by science-for instance to build a robot) in terms of rules, 'these rules need in no way be involved in producing the performance.' (Dreyfus 1967, 29). Hence-and luckily, we 
may add-we can dwell in the world without having to formalize everything (31).

Does this mean that experts use no rules at all? I propose to distinguish between a 'strong view' and a 'weak view'. According to the strong view, experts qua experts use no rules at all when they do what they are good at. Perhaps they use rules when they learn something new, but normally they do not need rules. According to the weaker view, experts use both rules and implicit knowledge, depending on the situation. Dreyfus seems to have held the strong view. For the use of technologies, it means that expert users of technology use it without rules and that everyday coping with and through technology happens without the use of concepts.

This strong view also implies that even the attribution of situation-specific aspects (in and by thinking) is excluded. In this response to McDowell (2007b), who, as we have seen, emphasizes the role of concepts and rationality even in unreflective action, Dreyfus also uses the example of using tools_-now taking up Heidegger's example of the hammer. Dreyfus argues that we do not even need a situation-specific concept:

'Indeed, in our everyday coping, which he (Heidegger) calls "pressing into possibilities", we don't deal with objects with general properties like weight, nor with situation-specific aspects like too heavy. Rather, when everything is going well and we are absorbed in our coping, the equipment we are using "withdraws" (where, as we shall see, this does not mean becomes implicit). Then there is no place for a demonstrative concept pointing out our equipment as anything. We do not attribute a general property or even a situationspecific aspect to it; we just cope.' (Dreyfus 2007b, 371-372).

Thus, according to Dreyfus, our everyday coping is not permeated by conceptuality at all. When we look at the phenomenology of tool use, we usually see absorbed coping. In absorbed coping, when performance is at its peak, there is no monitoring going on; there is 'flow' (Dreyfus 2007b, 373). He uses again the example of a tool: 'I don't see the doorknob as a doorknob when I'm absorbed in using it' (375). There is a direct response to the situation, no concept or thinking. Conceptual mindedness, Dreyfus suggests, is only possible against the background of non-conceptual, absorbed coping (376-377).

These examples show that technology, in the form of tools or equipment, is important for Dreyfus; it is part of our (life) world. The already-meaningful world is a world in which we cope with equipment: we are socialized into a world 'in which we cope with equipment' (Dreyfus 2001a, 187). In this sense, Dreyfus already has a philosophy of technology, or rather this work, the philosophy of skilled coping, is entangled with the philosophy of technology. For thinking about technologies today, his view has great potential. It seems suitable to be connected to other approaches in contemporary philosophy of technology such as postphenomenology (see the next section) that also emphasizes how technology is part of the lifeworld.

However, if we want to develop his account of skilled coping into a wider scoped philosophy of technology, we need more reflection on technology. Not all technology is 'tool' or 'equipment', or is something we handle and which disappears from view in our use and handling; there are more phenomena and experiences we can associate with technology. And, related: it is striking that Dreyfus's examples of everyday artefacts - at least in his work on skilled coping - are all old technologies; what does his account mean for contemporary technologies and media such as the internet and smartphones? Surprisingly, Dreyfus was far more pessimistic about contemporary technologies than one would expect from his account of skillful coping. To put it somewhat simplistically: he did not have a problem with hammers, but he did have a problem with the internet. Can this discrimination be justified, or is it a bias-one not dissimilar to the bias Heidegger had against modern technologies? And can it be justified on the basis of Dreyfus's own theory of skillful coping?

\section{Problems with Dreyfus's conceptions of technology}

If we want to make Dreyfus's account of skill fruitful for philosophy of technology, we encounter a number of problems that are related to the limitations of Dreyfus's Heideggerian conceptions of technology.

Like in Heidegger texts, there are roughly two ways in which technology appears in Dreyfus's work. The first one is technology as a tool, used in everyday coping. This meaning is based on the early Heidegger-Being and Time (1927). The second one is technology in its modern and contemporary forms, such as the internet. Technology is then seen as a treat to meaning and skilled engagement. Here one could see the influence of the later Heidegger, who embraced craft work but argued that modern technology is enframing and constitutes a danger (Heidegger 1977). Both conceptualizations of technology can be criticized, have been criticized (for instance in postphenomenology), and must be criticized.

The first meaning of technology (technology as tool) makes sense, but is limited to one human-technology relation. Of course we often relate to technology as a tool, and it is the case that in our use of the tool, the tool usually becomes invisible. But as Ihde has shown (Ihde 1990), there are more human-technology relations. Dreyfus focuses on what Ihde calls embodiment: a relation in which the technology withdraws in use. But technology can also appear, for 
example, as reality to be interpreted or "read" (hermeneutic relation) or as quasi-other (alterity relation). Phenomenologically speaking, a thermometer is not so much a tool as a feature of the world we perceive. And if we encounter a humanoid robot, we do not always relate to it as a tool, but often the robot is interacted with as if it was a human other. When it comes to his work on skill, Dreyfus unnecessarily limits his discussion of technology to tools. It would be interesting to discuss the role of skills and embodied coping in, for instance, the "reading" of technologies and in our encounters with machines. Here postphenomenological analysis is more sensitive to the various ways in which we experience technologies, whereas Dreyfus has more to say on the skill dimension. A combination of both approaches seems promising. For example, if it is the case that many technologies 'mediate' our experience and actions (Verbeek 2005 and subsequent work), then using Dreyfus enables us to argue that they do this by re-shaping our skilled engagement with the world and with others.

The second meaning of technology appears in Dreyfus's work on the internet (Dreyfus 2001b). Here contemporary technology is seen as alienating and meaningless, in contrast to craftwork (again referring to the use of tools). According to Dreyfus, 'distance-apprenticeship is an oxymoron' (Dreyfus 2001a, 67). Moreover, Dreyfus assumes that when we 'enter cyberspace' we leave behind our 'vulnerable, embodied selves' and avoid risk as disembodied web surfers, remote from the real (6).

Dreyfus has rightly raised issues concerning distance, embodiment, and meaning. It is important to evaluate uses of contemporary technologies in these terms. But there are at least the following problems with this analysis.

First, as Verbeek and others have argued, Heidegger's conception of modern technology is biased and conservative (Verbeek 2005). It is not clear why modern technology would be necessarily more alienating than ancient technologies. Dreyfus seems to adopt this view. In my book Environmental Skill (Coeckelbergh 2015) I have argued that the internet is not necessarily alienating. Technology might sometimes lead to more engagement with the world, for instance when it attends us to features of our environment we may not have noticed. For this purpose it is also necessary to describe and reflect on the phenomenology of technologies as opposed to 'modern technology' as Heidegger did (see also again Verbeek 2005). Second, to see technology as meaningless, or as leading to less meaningful lives (or even nihilism), contrasts with Dreyfus's (and Heidegger's) own view that the world is always already meaningful and that we use technology as embodied beings. This leads us, third, to the questions regarding embodiment. While Dreyfus is right to expose the problematic recurrence of Platonic dream of leaving the body behind (and correctly argues that Nietzsche would reject transhumanism since his vision of transcendence implied affirming, not denying our bodily and mortal nature), it is not clear why our use of the internet, or for that matter all contemporary digital or information technology, would be disembodied use. Dreyfus seemed to have confused the Platonic and Cartesian visions of some net enthusiasts with the phenomenology of the lifeworld. As I have argued against Dreyfus in Human Being @ Risk (Coeckelbergh 2013a), when we are online or in virtual worlds we are still embodied and our so-called "online" actions and thinking is still embodied: 'When we are online, we don't leave our body at home.' (Coeckelbergh 2013a, 130). Use of these technologies does not close off possibilities for skilled engagement (Coeckelbergh 2013a, 132). Elsewhere, I have also argued, against Dreyfus, that when we use the internet, we are actively related to our environment as embodied beings, and information technology does involve skills (Coeckelbergh 2011a, 152). In other words, it is also a form of skilled coping. And, in principle, it could also be a site for the acquisition of new skills and the learning of mastery. It is true that, as Dreyfus argued, for masters to respond immediately to present situations in a masterful way, they must have had experience of embodied successes and failures (Dreyfus 2001a, b, 67). But use of the internet, including distance learning, is also a kind of embodied learning — albeit (it must be admitted) of a different kind.

Dreyfus may have contributed to dispel the myth of the mental; he still seemed to have believed in what we could call the myth of the virtual (or the myth of the real as opposed to the virtual): the belief that somehow, when we use the internet and related contemporary information technologies, we are in a different reality (an online, virtual world), which is disconnected with the real reality. But Heidegger's and Dreyfus's own approaches try to move beyond dualist frameworks, and on the basis of Dreyfus's own account of skillful coping, one could claim that in these uses of contemporary technologies, the technology also often withdraws, and that embodied coping is going on, mediated by the new technologies. There is no outside to being-in-the-world and existence; we remain earthly and situated beings. There is one lifeworld (Coeckelbergh 2011a, 153). If there is alienation, it cannot be defined in this way. If there is alienation at all, it needs to be conceptualized as a problem of a particular use and relation, rather than as something linked to the technology as such. There is a problem with regard to distance and telepresence, but it should not be conceptualized in terms of a total absence of embodiment. At most, it is a different kind of embodiment. There might be a problem with regard to meaning, but it cannot be the total loss of meaning, since if that use is a skillful coping it has meaning, and in the spirit of Dreyfus, Heidegger, and the later Wittgenstein, we can say that use takes place against the background of a meaningful whole. It may be the case that the processing of date itself is meaningless; but 
phenomenologically there is no "in itself"; our experience and our engagement with computers our phones and our coping with data never is without meaning, and makes sense against a wider background of meaning.

This takes us to Dreyfus's view of 'the background', which I shall further discuss in the next section.

\section{Problems with Dreyfus's (under-) conceptualization of the social}

A related but different outstanding problem raised by Dreyfus's account of skillful coping is how skillful coping is related to meanings not limited to a particular skilled performance, meanings that have to do with the relevant practice, and more generally the social. Skillful coping does not happen in a social vacuum, but is always already linked to larger practices and to a wider social background. Although Dreyfus acknowledges this, the account of skillful coping itself is not very helpful for conceptualizing it. If we want an approach to philosophy of technology that says more about technology than what happens at the level of individual coping, and that is still inspired by Dreyfus, then his underdeveloped dimension of Dreyfus's work needs to be exposed, discussed, and repaired.

Partly Dreyfus's problem here is also a problem for phenomenology. One recurring problem with all phenomenological approaches-including postphenomenology-is a tendency to limit phenomenological analysis to individual subjects and their relation to the world. This is also applicable to other phenomenological approaches in philosophy of technology. For example, in Ihde (1990) and Verbeek (2005), the social and the cultural is of course acknowledged, but there is a focus on an "I" that relates to "world", mediated by technologies. The root of this problem lies in the classic phenomenological tradition (Husserl and Heidegger), or at least in individualistic readings of it. From the perspective of other approaches in philosophy of technology such as critical theory and (I will add) pragmatism, but also from approaches in the social sciences (social studies of science and technology, for instance), it must be asked if Dreyfus sufficiently conceptualized the social and took it seriously. For philosophy of technology, this is an important criticism to discuss, since, as social studies of science and technology approaches have always emphasized, technology is embedded in a social context and cannot be appropriately studied without taking into consideration the social dimension.

Consider Dreyfus's example of driving a car. The account of skillful coping is very good in describing the operation of the car in the sense of changing gears, braking, steering - and indeed the coordination of all these operations. When one is an expert driver, the skills involved no longer require instruction or rules; they are embodied and intuitive.
But driving expertise is not only about the operations as such; it also consists of participating in traffic. Traffic is a social phenomenon and hence driving, in the wider sense, is a social practice. To be skilled in driving means not only to be able to operate the machine but also to respond to situations in traffic - including its morally relevant features (Coeckelbergh 2016). But describing this requires a phenomenology that is not only about how I related to "world", but also about others. It requires a more social and relational phenomenology.

Let me first explore how this link to the social may be conceptualized from a Dreyfusian (that is, mainly Heideggerian) perspective-before suggesting some alternatives that go beyond Dreyfus and take inspiration from Wittgenstein and Dewey. Like Heidegger, Dreyfus does not address the social as his primary focus. But, like Heidegger, that does not mean that he does not mention it or that we cannot (re)construct some conception of the social based on this writings. A good place to start is Dreyfus's references to practices and to the 'background'. Then I will turn to his use of the Heideggerian concept of 'das Man' (the Anyone).

\subsection{Dreyfus on the (social?) background}

The question regarding the background arises from the (transcendental) question about what must be presupposed for a particular practical experience and skillful coping. For example, driving is only possible, and makes sense, against a background of a shared practice and shared norms and beliefs about what counts as good behavior. Driving is also related to other practices, such as (getting to) work and shopping. Ultimately, driving is also part of an entire culture and way of doing, which I would call, with Wittgenstein, a form of life. (See below.) Yet "norms" and "beliefs" may already be a bridge too far for Dreyfus, who sees background as something that cannot be made explicit at all. Why?

According to Dreyfus, understanding must not be seen as a merely epistemological or theoretical problem. Of course we interpret and explicate, but the basis is practical understanding: everyday coping. Practical understanding must be viewed in a holistic way. This approach is what Dreyfus calls practical holism. He uses one of his favorite activities to illustrate what this means:

'Practical understanding is holistic in an entirely different way from theoretical understanding. Although practical understanding-everyday coping with things and people-involves explicit beliefs and hypotheses, these can only be meaningful in specific contexts and against a background of shared practices. And just as we can learn to swim without consciously or unconsciously acquiring a theory of swimming, we acquire these social background prac- 
tices by being brought up in them, not by forming beliefs and learning rules.' (Dreyfus 1980b, 7).

Here Dreyfus seems to acknowledge the social and the cultural. Based on Dreyfus, we could see the social in terms of (the totality of) shared practices, which form the background of everyday coping and beliefs, and which 'make us who we are' (Dreyfus 1980b, 10). The social and the culture are thus embodied in our practices. This is also the case for scientific practices, which are only possible against background practices (16). However, Dreyfus refuses to define those background practices in terms of rules. In contrast to what Quine and Davidson supposed, for Dreyfus this cultural background cannot be made explicit and is not "in our minds" in the form of beliefs or background assumptions which could, in theory, be made explicit:

'Heidegger, Merleau-Ponty, and Wittgenstein suggest that this inherited background of practices cannot be spelled out in a theory because (1) the background is so pervasive that we cannot make it an object of analysis, and (2) the practices involve skill.' (Dreyfus 1980b, 7).

What makes up the background is not beliefs, but 'habits and customs, embodied in the sort of subtle skills which we exhibit in our everyday interaction with things and people.' (Dreyfus 1980b, 8). These cannot be reduced to propositional knowledge or rules. We respond to what situations require.

Increasingly, Dreyfus speaks of 'the background' rather than a background of shared practices. This use of the term as a noun in subject position is influenced by Searle, who speaks of 'Background' (Andler 2000). But, considered together with his position saying we cannot spell it out, this renders the background somewhat mysterious. Dreyfus argues that the background is 'hidden and holistic' (Dreyfus 2012). For Dreyfus, influenced by Heidegger and Merleau-Ponty, we cannot describe the background, since when the world functions as background it 'has' to withdraw to do its job. It enables other things to show up (Dreyfus 2012). This is, according to Dreyfus, how the phenomenology of skilled coping works. Whereas for Searle the background is a set of mental capacities that makes possible representation, for Dreyfus meaning is already there. As said, in his view there is no need to bring it in via intentional acts. The world is already meaningful and the body also confers meaning. Following Heidegger, Dreyfus holds that-as Andler put it-'the background is the condition of possibility for there to be anything at all of any significance to a being.' (Andler 2000). In this sense, it is like Wittgenstein's 'form of life'. (I will say more below.) And following Merleau-Ponty, the body—as involved in the learning of skill and in coping-is also a seat of meaning and a concrete incorporation of the background.

Dreyfus is right to point to the background as a seat of meaning that is already there, and which usually does not need to be made explicit to function. But based on this analysis of background, it is not so clear how the social comes in, and if the social as background must always remain entirely inexplicit. Does Dreyfus really mean that the background cannot even partly be made explicit in terms of rules or norms? Is the idea of a social science, which arguably has this project of explicitation at its very core, entirely mistaken? Is it senseless to speak of social rules or norms, for example, as social scientists do? And are philosophers who do so entirely misguided? It is not clear why Dreyfus takes on board Wittgenstein's anti-mentalist epistemology and philosophy of mind, but does not seriously engage with Wittgenstein's ideas about games and rules-ideas which influenced social scientists. (I will say more about a Wittgensteinian route below.) Dreyfus seems to miss an opportunity here to bring in these aspects of the social. For thinking about technology, we seem to be stuck with an account of skillful coping that is holistic and related to 'the background', but that background cannot be further made explicit at all and is bound to remain mysterious.

An interesting exception occurs when Dreyfus does speak of norms in his comment on style in his response to Searle, already mentioned before. He suggests that there are already social norms, there is already something binding on us, and we learn that from early ages on-without having to rely on explicit rules. This makes sense and opens up the possibility of a kind of middle position, which recognizes that there are rules, norms, etc. that have some normative power over us, but at the same time acknowledges that we do not (always?) learn them in an explicit way and that we do not need them in an explicit and formalized form in order to cope. But this thought is not made explicit, let alone elaborated. Otherwise, we must conclude that Dreyfus simply held on to the more extreme position that the background cannot be made explicit at all.

To conclude: the social and cultural can be connected to Dreyfus's thinking about background, but this connection is not further theorized or developed. There is, however, one way in which he theorized the social explicitly: a very Heideggerian way, to which we now turn.

\subsection{Dreyfus on 'das Man' (the 'Anyone')}

Dreyfus does say something about the social in his analysis of the early Heidegger. In a very interesting article on "the" world versus "my" world (Dreyfus 1975), Dreyfus argued that Heidegger's analytic of Dasein was meant to overcome the dilemma of having to choose between prioritizing a 
transcendental subject and prioritizing a social world. The everyday world is already public; there are already goals and equipment available in society, there are already 'roles' (Dreyfus 1975, 121-122). This thought makes a promising opening to a more social analysis. But then it turns out that Dreyfus restricts the social to a very specific conceptualization of it in the early Heidegger: he points to Heidegger's "das Man" (he translates it as the 'Anyone'). We do what "one" (Dreyfus: "anyone") does. This threatens authenticity. But it is not just negative. Explaining a hammer means to show what "one" does with it (124). In Wittgensteinian terms, there is already agreement in form of life (125). Heidegger, however, stressed the contrast the 'Anyone' with authenticity. We lose ourselves. Dreyfus is maybe more optimistic and argues that we can still give individual style to the modes provided by the 'Anyone' (129). But, nevertheless, we are constituted by the 'Anyone':

'Dasein, which as Being-in-the-world is always a way of acting, can and must give its individual style to the modes of behavior provided by the Anyone. Thus Dasein is both constituted by the Anyone in that all significance is a social achievement, and yet self-constituting by taking over significances from the Anyone to define itself or give itself meaning. With this analysis of the parasitical relation of the individual to the social world, Heidegger gives an account of the relation of the personal to the public which (dis)solves the Husserlian problems arising from the priority of my world to the world.' (Dreyfus 1975, 129).

This could be seen as pointing to a kind of (Heideggerian) social philosophy. Heidegger can be interpreted as arguing that we already find ourselves in a social world, and that we are always socially constituted. And it is interesting that Dreyfus says something about the relation between Dasein and Anyone, which could be seen as asking a central problem of social philosophy, but then formulated in a Heideggerian way. However, first, even within a Heideggerian framework it can and has been objected that Dreyfus leaves out what Heidegger calls Mitsein. Olafson has argued, against Dreyfus, that he gives a far too large role to 'Das Man', which is only a deformation of our social being (Mitsein) (Olafson 2008). Carman, in turn, has accused Olafson of an over-individuated notion of Dasein (Carman 2008). Whatever the best interpretation of Heidegger may be, it turns out that Dreyfus (like Heidegger) has again said too little about the social, and has left too much room for interpretation. His suggestion that human beings depend on the social world is important but underdeveloped. Second, the social is mainly seen as a given, and as one monolithic kind of thing. The rules or the antagonistic tendencies and variations within the social are not visible, except in the form of style. But this thought is not elaborated, and the Anyone itself remains one undifferentiated "block" or "box". Dreyfus's thoughts here are too vulnerable to the objection that in this view there is one 'Anyone', which seems not up to change or remains black boxed. Again, this is unhelpful if we want an approach to thinking about technology that takes seriously the social embeddedness of technology.

To remedy this, one could resort to Marx or Hegel, who analyzed the social in terms of struggle; this may help to open the black box, so to speak. Or one could go directly to contemporary social sciences, which have more to say on style and the social, and which have also a lot to say on technology and the social [social studies of science and technology (STS), see below]. But as already suggested, there is a thinker closer to Dreyfus who also may be of help to say more about the social: Wittgenstein.

\subsection{Wittgenstein}

Wittgenstein's post-Cartesian, anti-mentalist view in $O n$ Certainty (1969) and his rejection of his earlier Tractatus view that the world is a collection of fact, is in line with Dreyfus's view, and supports his arguments against classic $\mathrm{AI}$ and his focus on how we cope with everyday problems. The later Wittgenstein understood knowledge not in terms of static and inner mental states or objective facts, but suggested a more practical, pragmatic, process-oriented, tacit, and embodied conception of knowledge. Whether in scientific research or in everyday life, our doubts rest on a basis of things that are not doubted, things that are accepted and presupposed. This approach is interesting for philosophers of technology as it may help us to discuss the issue of trust in technology, and supports a view of technology as a skilled and embodied practice and technique that crucially involves implicit knowledge (Coeckelbergh and Funk 2018). But we can also use Wittgenstein for the purpose of developing a view of the relation between a specific practical activity (or coping) and the wider, perhaps implicit social background. Dreyfus has not done this. Although he sometimes referred to Wittgenstein, he did not really use him to further elaborate the holistic relation between everyday coping and the background. But we can. Let me explore some possibilities.

One way to start such a project is to draw on scholarship about Dreyfus that makes connections to Wittgenstein. For instance, Rietveld's work on the differences between Dreyfus and McDowell (Rietveld 2010) at least suggests that it can be useful to discuss interpretations of Wittgenstein in order to further elaborate a Dreyfusian approach. The same can be said about McManus's comparison of Wittgensteinian and Heideggerian ideas when discussing the concept of "background" in Dreyfus (McManus 2007). These critical discussions could be used as a starting point to bring more Wittgenstein into Dreyfus. 
Another way is to draw directly on Wittgenstein, as I have done in my recent work on technology inspired by Wittgenstein (Coeckelbergh 2017a, b; Coeckelbergh and Funk 2018) and in line with some suggestions in Winner (1986). Based on the Philosophical Investigations (Wittgenstein 1953/2009), I have argued for a holistic and transcendental approach to technology which sees technological artifact, in their use and in our performances, as embedded in what Wittgenstein calls 'games' and 'form of life'. The meanings in and of the particular use and performance are related to our activities, games, and form of life, which are also social and cultural, and which must be presupposed for the particular use and activity to make sense. This is a "background", if you wish, but one that is more practical and less mysterious than Dreyfus's. It is transcendental in the sense that it is a condition of possibility for technology uses and performances, but it is not transcendental in a Kantian (abstract categories) or Heideggerian (a mysterious ontology of being) way. Instead, the view I proposed connects a particular use and performance (and hence the skill and know-how related to it) to a wider background of games and forms of life which already contain practical know-how. Moreover, this know-how is not necessarily implicit. It contains a lot of implicit knowledge, for sure, but at least part of it can be made explicit in terms of rules. This understanding of the social renders it possible for the social sciences to say something meaningful about the social and our social practices. But more importantly for the purpose of using Dreyfus's account of skillful coping: it presents a more elaborated and arguably more balanced theory of the relation between skillful coping and its social background, which can at least partly be made explicit. Usually we do not think about the rules of our social games. Usually we do not make explicit our form of life. And maybe we can never make it fully explicit. Maybe not everything can be captured in rules. But surely it makes sense to sometimes formalize for practical purposes, that is, as a tool. (See also my use of Dewey below.) Furthermore, this view also acknowledges the normative dimension of the background-even if these norms may not always be visible or even if they can only be partly explicitated. Finally, with the concept of games we could also add that the background is not entirely given: we can also change it. We can change our games, and partly that can happen by changing the rules. But it can also happen differently. Technology, for instance, can be a game changer. It can disrupt and transform our background understandings and practices. However, I share Dreyfus's Heideggerian intuitions in so far as I believe that such changes are small and slow, similar to the changes in river beds- to use a Wittgensteinian metaphor (Coeckelbergh 2017b).

Maybe this approach also helps us to relate the conceptual to the non-conceptual, the challenge Dreyfus formulated (Dreyfus 2007a): if we see the conceptual, logic, reasons, etc. not as things that are "out there" in the world (as McDowell and Dreyfus seem to assume) but as something that only "lives" embodied in performance and a use, that only exists in our engagement with the world-in particular, our use of words and a performance with words, which itself is, like all performances, related and made possible by an implicit background of practices-then that seems to me at least a preliminary answer to Dreyfus's question. The conceptual does not have an existence outside our uses and performances, and the use of concepts itself depends on embodiment and on an often inexplicit background: background knowledge, experience, and practices, that are always already social. This answer is in the spirit of Dreyfus, butinfluenced by Wittgenstein-gives more importance to the concept of use, acknowledges a role for the conceptual, and attends to use of language, which is often neglected in contemporary philosophy of technology (Coeckelbergh 2017c) and indeed in Dreyfus's account of skilled coping.

Another route, which is also not necessarily distant from Wittgenstein, is STS and, earlier, sociology of knowledge, which usually sees knowledge as socially constructed. In the 1990s, Harry Collins already criticized Dreyfus for not taking on board Wittgenstein's notion of form of life and, more generally, for not seeing that the structure of knowledge is to be found in the social collectivity (Collins 1992). He writes:

'For sociologists of scientific knowledge, most of whom think of themselves as jumping off from Wittgenstein's later philosophy, it is surprising that a philosopher who leans so heavily on Wittgenstein should even have a concept of a knowledge domain apart from a form-of-life.' (Collins 1992, 727).

There is domain knowledge, but this knowledge has a history-a social history in which things could have been different. This form of life shapes my usage. For instance, the English language or arithmetic can be seen as domains of knowledge, but they also kind of compel me to speak in certain ways. But at the same time that language is made in society. Collins thinks that we have more control over it than Dreyfus suggests. According to him, Dreyfus failed to distinguish between individual knowledge and collective knowledge and focused only on individual understanding (Collins 2013). Taking up the example of car driving again: Dreyfus talks about how we learn to drive in the sense of operating the car, but this leaves out the knowledge we need about traffic. This is Collins' take:

'Dreyfus has no concept of collective understanding that is separate from the concept of individual understanding; this is why he makes no clear distinction between expert car driving (gear changing etc. which requires only the context of the machine and its relation- ship to the road to be internalised) and 
expert car driving in traffic, which requires national driving conventions to be understood and updated through immersion in the collectivity. Gear changing, like Dreyfus's iconic example of an expertise, that of the chess grandmaster, does not depend on collective tacit knowledge, whereas driving in traffic, and most other expertises, does.' (Collins 2013, 411).

While I disagree with Collins that it is so easy to distinguish between the two kinds of knowledge, or indeed that one should make this distinction between individual and collective knowledge (I already mentioned Dreyfus's interpretation of Heidegger that tries to go beyond this dichotomy and with my interpretation of Wittgenstein I show how use and the social are entangled), if the point is that driving is also about collective knowledge then this makes sense and helpfully brings in a social perspective. For thinking about technology, it means that technologies need to be understood not only in terms of "micro"-skillful coping; that skillful coping needs to be related to a "macro" wider social background knowledge. One could also draw on work in contemporary STS (Wiebe Bijker and others) that shows how the design of technologies is the outcome of a social process, to support this point.

More generally, on the one hand, we can learn from the social sciences that there is something like collectivesocial knowledge, that the background can at least partly be made explicit and is at least partly something which we can influence. 'Das Man' is not simply given. Influenced by Heidegger, Dreyfus makes the background more mysterious and untouchable than it is. On the other hand, we can learn from Dreyfus that the social cannot be made entirely explicit in terms of rules and beliefs, and that there are limits to the extent to which we can control it.

Another relevant objection to Dreyfus, which also links to STS and the social sciences, has been made by Selinger and Crease (2003). Here the target is Dreyfus's account of expertise. While the authors praise Dreyfus for bringing in a first person perspective to studying expertise (rather than a third person perspective, as the social sciences usually do), and for calling attention to the relation between expertise and the body, they complain that his account is not sufficiently sensitive to the cultural embeddedness of the expert, including prejudices, ideologies, and hidden agendas the expert may start from. Experts are not embodied and situated subjects, as Dreyfus shows us; they are also people that are culturally and socially embedded, and since that gives them prejudices, agendas, and so on, we should not naively trust them. Society might even be endangered by experts - an issue that cannot arise in Dreyfus's account (Selinger and Crease 2003, 262-263). In particular, Dreyfus's point that experts might not be able to propositionally justify decisions (270) seems dangerous-how can we trust them, and what if they assume power on the basis of intuitions?

The assumption made by the authors that trust necessarily relies on explicit knowledge and the suggestion that Dreyfus's model of skill acquisition necessarily leaves out the role of the coach are problematic. Trust does not require that everything is made explicit; on the contrary, otherwise there is no need for trust. Trust is not necessarily the outcome of a rational process but, according to a 'social-phenomenological' view, is already embedded in the social and in relations (Coeckelbergh 2011b). I also do not see why Dreyfus's model of learning excludes the possibility of coaching. For example, a coach can be helpful for beginners, and even for experts, since a coach does not necessarily only give rules and instructions; she might also encourage a trial and error kind of process of the kind that Dreyfus would approve of. And Selinger and Crease speak about a very specific kind of expert than the everyday expert of Dreyfus: not the expert driver or swimmer but, for instance, an expert who is asked about health or climate change, who is socially recognized as "expert" in the sense of a doctor or scientist, for example, and has a specific role to inform policy as an "authority", who has an "audience", and so on. But their point about embeddedness is important since it points again to a lacuna with regard to the social dimension of Dreyfus's model. Focused on embodied coping, the account of skilled coping and expertise seems less sensitive to social, cultural, and political context than it could be. This includes the point suggested by the authors that experts are and should be vulnerable in the sense that they can be challenged with regard to their expertise and that they can be asked to give reasons-even if not everything can be explained and sometimes experts just have to say (not "admit", this sounds too negative) that they rely on their experience and intuitions. But it makes sense to say that the social and the political also includes giving reasons and deliberation. This is a lacuna in Dreyfus's work. And perhaps the more fundamental problem is that the entire social and political playing field, in which experts are situated and which plays a role in what they say and become, remains out of sight.

How can this be conceptualized? Next to STS and Wittgenstein, pragmatism is another source which can help us to conceptualize the social dimension of skillful coping, and which has a lot more to say on deliberation and public discussion than can be done within a Heideggerian framework.

\subsection{Dewey}

A thinker who is curiously absent in most discussions by and about Dreyfus is Dewey. (An exception is a Dreyfus paper on ethical expertise-see Sect. 5.2). This is curious since there are at least the following points of connection. First, like Dreyfus and Wittgenstein, Dewey was skeptical about the 
language of the "mental" and sees mind as embodied. But he also understood it as emerging from the interaction in a social context. In Experience and Nature (Dewey 1929) he sees knowledge as 'a mode of interaction' (435) and argues that meaning is not a 'psychic existence' (179). Dreyfus, focused on the handling of tools, ignores this more socialinteractive view. But if we see technology as an instrument of social cooperation, as I proposed in my interpretation of Dewey's view of language (Coeckelbergh 2017a, 33-37), then this puts tool use as skillful coping in a more social context. Moreover, whereas Dreyfus seems to put language in a separate category (the conceptual, the symbolical, etc.) divorced from embodied coping, for Dewey language is both embodied and social. It is about organized interaction with other living creatures (258). Second, Dreyfus could have used Dewey's conception of habit. In Human Nature and Conduct (1922), Dewey argues that we know how by means of our habits (Dewey 1922, 177). This idea seems to fit Dreyfus's account, and could help to understand our use of technology from a more social angle. Dreyfus talks about habit, but does not use Dewey to elaborate this social aspect of skillful coping. That coping and those skills can be understood as being part of habitual and shared ways of doing, and our tools become tools in the context of social groups (186). Third, Dewey's work also seems particularly relevant when it comes to conceptualize public discussions about technology. In Dreyfus's work, the public dimension is mentioned but not theorized. Dewey could be used to elaborate this aspect of the social in a non-Hegelian way. But Dreyfus rejects this route. Here a significant barrier to using Dewey is that whereas Dewey stresses deliberation to solve social problems, for Dreyfus a lot is going on without deliberation. Moreover, Dreyfus seems to divorce mind and knowledge from the social. In his response to Collins (Dreyfus 1992, 724), Dreyfus argues that not all intelligence is social; this goes against the pragmatist view that intelligence is social and, again, is about solving social problems. (More below.) Finally, one could ask if Dreyfus's account of skilled coping is sufficiently appreciative of the social-linguistic and communicative dimension of coping. In my interpretation of Dewey, language must be seen as a social tool (Coeckelbergh 2017a, 35). Perhaps language could be integrated in a Dreyfusian-Wittgensteinian view by saying that next to the handling of things, there is also skillful coping with words, and both kinds of skillful coping are always embedded in a social-practical context in which there is inexplicit knowledge but also language and language games, constituting a form of life which is given and shapes our concrete coping-performances. And here, too, one could add that in the use of words, in coping using words, that language withdraws, is not always visible. Indeed, it is usually so invisible that Dreyfus managed to leave it out of his account of skillful coping. But this "default" invisibility does not justify excluding it from a theory about the kind of knowledge and experience involved in skilled coping.

But there are also possibilities next to using Dewey, that are certainly not far away at all from the thinking of Heidegger and Merleau-Ponty, but that are, nevertheless, more appreciative of the social aspect of skill than Dreyfus was. For example, Borgmann, a philosopher of technology who in his praise of skilled activity is very close to Dreyfus, manages to connect skilled activity to the social in a very straightforward, less Heideggerian or mysterious way. He writes:

'Physical engagement is not simply physical contact, but the experience of the world through the manifold sensibility of the body. Skill is intensive and refined world engagement. Skill, in turn, is bound up with social engagement. It molds the person and gives the person character.' (Borgmann 1984, p. 42).

Borgmann (1984) stresses that when we are engaged in skilled activity, we do not only engage with things but also with others, for example, when keeping a stove going centers the family. A similar view can be found in Crawford's analysis of craftsmanship, which is about working together and sharing a concept of good (Crawford 2009, 181). One could also argue that skilled activity helps us to shape our character. This takes us to the questions regarding virtue, and more generally the ethical and political implications of Dreyfus's position.

\section{Problems with the ethical and political implications and the question regarding virtue}

What are the ethical and political implications of Dreyfus's view of skilled coping? While his account is mainly descriptive and aimed at understanding the kind of knowledge involved in skilled coping, it has normative implications. The problem is again that it is not entirely clear what these implications are based on Dreyfus's own writings; but these implications need and deserve to be further articulated and developed, also with a view to arrive at a better thinking about technology.

Like Reynolds (2006) I believe that if we look at his account of skill acquisition, Dreyfus's view is one in which a kind of ethical comportment is more important than sophisticated reasoning: moral maturity 'is primarily about an ethical comportment to situations in the world rather than about coming to have more sophisticated cognitions and judgments about principles and rule-following' (Reynolds 2006, 545). Ethics seems to require the development of a practical wisdom which can respond intuitively and appropriately to specific situations. This sounds like virtue ethics. Dreyfus might 
have been aware of this connection: when I had a chance to talk to him in Berkeley, years ago, he suggested to me that virtue ethics may be a good way forward when it comes to elaborating the ethical implications of his work. But more work is needed on this: how, exactly, does his account of skillful coping relate to virtue ethics? It seems to me that his account lends support to virtue ethics, albeit a virtue ethics of a particular kind: one that does not necessarily involve reasoning and judgment, but rather a knowing-how to best respond to the world and to others in particular situations. Let me develop this thought about a Dreyfusian virtue ethics by engaging with some of the literature on virtue and skill. I will end by raising the question regarding political implications.

\subsection{Virtue and skill}

What does it mean to say that virtue is about skill? Annas famously argued that virtue is like skill (Annas 1995). The point is that there is an analogy in structure between the two. Now, whether or not this is a sound interpretation of Aristotle (for a discussion see Stichter 2007), this is an interesting view in the light of Dreyfus's emphasis on skill. Annas's claim concerns intellectual virtue; her project was to understand intellectual virtue. But what if virtue tout court is like skill? And what if virtue is not so much about intellect at all? Indeed, perhaps there is more than an analogy: in the spirit of Dreyfus one could argue that this is still a far too intellectualist conception of virtue. For Annas, virtue as skill requires reflection (Annas 1993) and the development of an intellectual component (Annas 1995). For her, the stress is on reflection and decision: 'The skill analogy requires that the agent reflect and achieve by reflection a unified grasp of the general principles underlying her patterns of action and decision.' (Annas 1993, 67-68). But is this reflection and decision necessary and sufficient for virtue? Stichter convincingly argues they are not necessary:

'A person's ability to explain herself can be less than the person's ability to know how to act in the situation.

The intellectual requirements that Annas discusses are relevant to any social discourse we have about morality, but they are not necessary for achieving expertise.'

(Stichter 2007, 194).

Annas admits that many skills are not like the skills she describes, but then still endorses her intellectualist conception of skill, going against our intuitions and experience: indeed she defends an account of skill that 'does not fit numerous examples of actual skills' (Stichter 2007, 187). She thus perpetuates an intellectualist tradition of thinking about skill that started at least with Plato and Aristotle. It ignores recent thinking about skill including Dreyfus's work-which was already available when Annas wrote. The point is not that I disagree with Annas's interpretation of Aristotle: he may well have an intellectualist, theory-oriented understanding of virtue, skill, and practical wisdom (phronesis); this is at least also my impression when I read him. As McPherson puts it: 'Aristotle himself, it is worth recalling here, classified phronesis as an intellectual virtue, aiming at truth, rather than as a practical virtue, aiming at goodness.' (McPherson 2005, 706). But if this is right, there is no need to follow Aristotle on this. Learning from Dreyfus, we can do better and develop theory that is closer to the actual phenomena of skilled coping and their relation to virtue and good.

Indeed, as becomes clear on the basis of my summary of Dreyfus's account, and as Stichter also shows (2007, 192), Annas's view goes against a Dreyfusian way of thinking about skill: for Dreyfus, skillful coping does not at all require reflection. Hence, if we use skill as a model for virtue and use Dreyfus's view of skill, then virtue would also be virtue without an intellectual component. It suffices that we know how to do good in the sense that we know how to do good in practice. Theoretical knowledge or reflection, then, are neither necessary nor sufficient for virtue, and can even get in the way of this virtue-as-skilled-engagement and virtue-as-performance. A standing back, so it seems, is then not required. For Annas, this would not be genuine skill. According to her, virtue is about having a disposition to act for reasons (Annas 2007). But, from a Dreyfusian point of view, there is no good reason why we have to follow her conception of virtue. Thus, let us go further than Annas, and argue that virtue is not only analogous to skill but entirely a matter of skill, but then understood as embodied coping, and as not needing anything else than know-how: knowing how to do good (in practice).

This is a conception of virtue I defended in my own thinking about technology, skill, and virtue. If we think about ethics of technology as a virtue ethics, if we define virtue in terms of skill, and indeed if we define technology in terms of skill (Coeckelbergh 2012), then we get the following conception of virtue: virtue is a matter of practical wisdom, which implies a knowing-how and skill. Being "wise" is etymologically related to a "way" (Coeckelbergh 2015, 118 footnote 2). (Here one could also consider Eastern conceptions of virtue, for instance in Daoism and Confucianism.) Influenced by Dreyfus and Dewey, I have argued that virtue is about knowing how to do things. Virtue is not about having particular properties, but about practicing virtue. There is not first a 'logos' which then needs to be applied to the real world. Rather, virtue is about having 'ethical know-how' and doing it, practicing it (Coeckelbergh 2011a, 162). And if we then see technology in terms of skill, we have a view in which virtue, skill, and technology are integrated. There are no longer two sides-reason and intellect versus embodied coping and material technologies-but there is only one 
skillful coping, engagement, and practice, and virtue is all about the quality of that coping, engagement, and practice. For example, environmental virtue is not something abstract and external (say, a principle) that is imposed on the lifeworld as it were from outside, but rather something that goes on in the lifeworld and that transforms it. It is about how we (skillfully and technologically) relate to our environment. Virtue is then 'a way of doing' and a 'form of life' (168). Or as I said it elsewhere, in the context of thinking about health care: good health care is 'in the how'; it is about knowinghow to deal with people and handle technologies (Coeckelbergh 2014). Of course we can reflect and deliberate. This may help. But if we have that kind of practical wisdom, that kind of know-how, there is nothing in terms of virtue that is wanted in addition or outside of that wisdom.

\subsection{Ethical expertise: Dreyfus contra Dewey}

This interpretation of virtue in terms of know-how is in line with Dreyfus's own phenomenology of ethical expertise, but he takes distance from Dewey. In a paper with his brother (Dreyfus and Dreyfus 1991) he repeats the account of skill acquisition, but then draws out the implications for ethical expertise. In so far as ethical comportment is a form of expertise, the brothers Dreyfus argue, it has the same developmental structure (236). As a child we learn moral rules, but rules and maxims are for beginners in moral development. Ethical experts do it differently: 'with enough experience, the ethical expert would learn to tell the truth or lie, depending upon the situation, without appeal to rules and maxims' (237). Interestingly, here the Dreyfus brothers do use Dewey to develop their account. They endorse Dewey for saying that ethical comportment is spontaneous, involving an immediate reaction. But then they argue that Dewey was wrongly focused on problem solving and ignored 'ongoing coping', which is not only simple but also complex. According to Dreyfus, as experts we can respond to complex situations without deliberation (238). Against Aristotle's intellectualism (or, in Dreyfus's view: against intellectualist interpretations of Aristotle), the Dreyfus brothers argue that people should not only be praised for what they intend to do but also and especially for their 'brilliant intuitive responses' as experts (239). Virtue, then, is spontaneous: 'We can only tell if a person is courageous, for example, by seeing his spontaneous response in many different situations.' (239) For Dreyfus, no practical reasoning is necessary. Principles can even hinder good ethical responses:

'an ethical expert when confronted with cases of "lifeboat morality" may have to fall back on ethical principles. But since principles are unable to produce expert behavior, it should be no surprise if falling back on them produces inferior responses. The resulting deci- sions are necessarily crude since they have not been refined by the experience of the results of a variety of intuitive responses to emotion-laden situations and the learning that comes from subsequent satisfaction and regret. Therefore, in familiar but problematic situations, rather than standing back and applying abstract principles, the expert deliberates about the appropriateness of his intuitions.' (Dreyfus and Dreyfus 1991, 241).

Against Dewey, who thinks that in difficult situations we need deliberation and examination, Dreyfus and Dreyfus argue that of course experts should have a dialog about their responses, but there may be no final agreement; the experts have to appreciate each other's decisions (242). And against Kohlberg and Habermas (and partly in agreement with Gilligan), they argue that the highest stage of moral development is not about detached and abstract reasoning, but intuitive response to the situation. They write: 'if being good means being able to learn from experience and use what one has learned so as to respond more appropriately to the demands of others in the concrete situation, the highest form of ethical comportment consists in being able to stay involved and to refine one's intuitions.' (247). Detached reflection is resorted to in case of a kind of breakdown, it is not the rule. One could conclude that, according to the Dreyfus brothers, skillful coping without deliberation is the 'default', at least for experts.

Dreyfus and Dewey may actually be closer than presented here. Both agree that the main challenge is to appropriately respond to situations. Both may also agree that emotions and intuitions play a role. Dewey also criticized abstract principles and detached reasoning. Principles are tools to cope with a situation. Dreyfus could have arrived at a less extreme view if he recognized that, like other tools, principles and reasoning can help us to skillfully and expertly cope with ethically challenging situations, especially in a social context. These tools may not be sufficient. And it may well be that before, during, and after the decision, the expert cannot entirely render her decision process and the knowledge basis of this decision process transparent. But talking with others and the use of principles may help, like other tools may help. If Dreyfus would have recognized that language, concepts, etc. are also a kind of tools, he could have held the view that deliberation is perhaps not necessary, but helpful as one of the tools we have. He could have arrived at the more moderate view that moral experts at a higher stage of development, when faced with a problem in a social context, often masterly know how to combine various tools and types of knowledge, including intuition, emotions, principles, discourse, etc. - without being able to fully explain themselves afterwards but with being able to have a meaningful conversation with others about their decision. However, perhaps the 
final aim and the highest stage is moral wisdom and virtue understood as knowing-how to do good, which may also be reached without deliberation and conversation; they are neither sufficient nor necessary. Moreover, with Dewey we can add that when we seek consensus, it is impossible to reach a final agreement, with "final" meaning: an agreement for once and for all. Dreyfus could have agreed with this view. But with Dewey we must appreciate, more than Dreyfus did, the social and collective dimension of coping and indeed of the problems we face. There is often the practical-social need for collective coping to reach a temporary consensus among experts. Language and other tools may help with this.

\subsection{If skilled engagement and craft work are good, what does that imply for contemporary technologies?}

Next to implications for a conception of virtue and moral development, Dreyfus's work also contains a particular view of the good life-especially the good life in the context of modernity. Dreyfus does not only make a descriptive claim about knowledge and skill; we can also discern in this work the normative claim that skilled engagement itself is something good, that particular technological practices—craft work especially—are ethically good in several ways, are conducive to the good life. In line with work by Pirsig, Sennett, Crawford, and in philosophy of technology Borgmann (see my discussion in Coeckelbergh 2015), Dreyfus thought that there is something special about skilled engagement that makes it good in itself, and that helps us to cope with the nihilist tendencies in modern culture. Now this claim-which, by itself, has a lot to say for it-is not necessarily right in its evaluation of modernity and can lead to a conservative and pessimistic position with regard to new technologies. This seems the direction Dreyfus took, for example, in his book with Kelly (Dreyfus and Kelly 2011).

According to Dreyfus and Kelly, our modern (self-)understanding has left us with a meaningless world. In response to this nihilist condition, they argue that we must re-enchant the world by seeing that the gods are there (polytheism), that there is the sacred, and that there are still Greek-style heroes, for example in sport (Dreyfus and Kelly 2011, 201). But they also propose craftwork and its skilled activity as a response to alienation and nihilism. According to the authors, we can come to discern meanings that are already there (209) and may feel that there is a force outside our self (8). The craftsman achieves 'intimacy' with the material (2010), whereas modern technology such as GPS alienates us from our environment. They write:

'to lose the sensitivities - to the landmarks, street signs, wind direction, the height of the sun, the starsall the meaningful distinctions that navigation skill reveals. (.. .) Indeed, in an important sense this experience turns you into an automated device the GPS can use to arrive at its destination.' (Dreyfus and Kelly 2011, 215).

While I agree with the authors on the value of skilled activity, and even on the potentially alienating aspect of technologies such as GPS, alienation and nihilism are certainly not the only possibilities when it comes to contemporary technologies. First, the world is a lot less disenchanted than Dreyfus and Kelly suppose. Consider for instance how much wonder there is in contemporary science and technology, and how romanticism and technologies are still entangled (Coeckelbergh 2017d). More generally, it is highly doubtful if we find ourselves in the nihilistic situation Dreyfus and Kelly describe. We always find and create meaning, also in our daily coping with and through technologies. Second, even if there is still alienation due to technologies, new technologies are not only a problem; they may also be part of the solution. Different technologies and uses are possible. As postphenomenology reminds us (Ihde 1990), and as I have argued using Wittgenstein (Coeckelbergh 2017a, b), technologies are ambiguous and 'multistable' in the sense that they are always technologies-in-use: the same artifact has different meanings depending on use and context. This has implications for thinking about technology and virtue. In my work on skill, technology, and virtue (Coeckelbergh 2011a, 2012, 2015), I have proposed a more constructive approach than Heidegger and Dreyfus: one which does not a priori exclude the possibility that new technologies may contribute to skilled activity, virtue, and good. For example, when it comes to wayfinding it is true that GPS may divert our attention from our surroundings, but perhaps some apps can help us to see features of the environment that we did not notice (yet). There may be more modes and possibilities (Coeckelbergh 2015, 149) and more creative uses of the same device to explore different ways of wayfinding and walking (152).

More generally, I have argued that contemporary information and communication technologies could, in principle, also help us to overcome alienation and find a better relation to our environment and to others. In 'Technology as skill and activity' (2012), I have argued that we can take seriously the problem of alienation but at the same time have a Dreyfusinspired (but also more social and Dewey-inspired) ethics of skill that is open to the possibility that new technologies can also help us to overcome alienation. We can use the concept of skill to evaluate new technologies, asking if they contribute to more or less skilled engagement. But there is no a priori answer as to which technologies are more 'focal' (to use Borgmann's term; Borgmann 1984) or more engaging and more conducive to skilled activity and craftsmanship-activities and modes of knowledge and interaction 
which Dreyfus rightly valued. What matters then is not what technology "is" (as is sometimes suggested in Dreyfus's late Heideggerian approach to new technologies), but rather what kind of skills-activities are promoted and supported by specific technologies, by a particular technology-in-use. What matters is whether or not the skills-activities lead to more engagement and less alienation. (Coeckelbergh 2012).

Thus, new technologies are far more ambiguous with regard to skilled engagement than Dreyfus suggests. Consider also the work of Shannon Vallor, who has argued that while contemporary ICTs can lead to 'moral deskilling' there may be also potential for 'upskilling' (Vallor 2015). Recently, she has called for a technomoral virtue ethic (Vallor 2016). These interpretations of the relation(s) between technology, skill, and virtue suggest that it is possible to talk about virtue and skill in a way that is critical of contemporary technologies, but also takes a more constructive and hopeful approach: perhaps there often is, but there does not need to be, an opposition between the cultivation of virtue and the development of advanced technologies.

Consider again the use of electronic technologies in health care. In 'E-care as craftsmanship' (2013b) I have argued that while under modern conditions and with the use of tele-care there are real dangers with regard to the erosion of craftsmanship, the use of new technology is not necessarily jeopardizing skillful and careful engagement with patients and quality care. Whether such an engagement is possible depends on whether in a specific practice and given a specific technology e-care workers can develop the knowhow and skill to engage more intensely with those under their care, and to cooperate with their co-workers. What matters is how care workers work and care, when using and working with new technology—and with each another. Hence, craftsmanship in "e-care" is possible, for example, when tele-care technologies are used as a complement rather than a replacement of care workers, and when criteria and conditions for craftsmanship are fulfilled (Coeckelbergh 2013b). Another way of putting this is, again, to say that good health care is not about the technologies as such; good health care is in the "how" (Coeckelbergh 2014). The challenge is to design and use technologies in such a way that more engaged and care-full ways of doing and knowing-how are promoted.

\subsection{The social and political dimension of virtue and craftsmanship: Dewey and Maclntyre}

As I already suggested, craftsmanship also has a social dimension (Coeckelbergh 2012). It is not only a kind of technical skill; it is also about doing things together, sharing good, and indeed the skill to work and relate to others. But this social dimension is not always presents in views of craftsmanship, skill, and virtue. Often the emphasis is on the individual or personal level. This is also the case in Dreyfus's account of skillful coping. As I proposed, the social dimension could be developed by bringing in a pragmatist (or other) conception of habit and other concepts that help us to understand the social and public dimension of skilled engagement and virtue. Individual or personal experience and wisdom are always linked to collective knowledgeexplicitly and implicitly. If virtue and the highest stage of moral development are a matter of skillful coping, as Dreyfus argued, then this skillful coping should not only be conceptualized in terms of individual knowledge. Dewey's pragmatism or the social sciences could help Dreyfus-inspired philosophers to further work on this problem. Another interesting source may be MacIntyre, who is acknowledged by Dreyfus but not fully used. His conception of practice as a social and historically situated activity that enables participants to attain goods internal to the practice and achieve excellence and virtue (MacIntyre 1984) might have enabled Dreyfus to say more about the social dimension of skillful coping and virtue, in particular about the links between skillful coping, virtue, and practice. It may certainly provide a source of inspiration to those philosophers working on virtue and technology who are interested in developing the social dimension of their work. (Note also that MacIntyre, Dewey, and the later Wittgenstein are in agreement when it comes to rejecting the fact/value distinction, which may also help to conceptualize a view of virtue that links it firmly to its social and practical contexts. However, I will not further elaborate this point here.)

Moreover, given the often-lacking attention for the social dimension of virtue in modern theories of virtue, virtue approaches are in danger of ignoring the political dimension-including potential political problems that are often ascribed to thinking in terms of skill, craft, and virtue. Since modern virtue ethicists tend to be focused on individual moral development or (more local) practices, they are often blind to the wider and often antagonistic social playing field, within which individual cultivation of character is set. Or far worse, they do not ask the political question at all.

This is also a problem for a Dreyfus-inspired thinking about technology, to the extent that it comes in the shape of a virtue ethics focused on individual skillful coping. Such a focus leaves too much room for interpretation concerning the political implications. Reynolds (2006) has argued that there is a danger that Dreyfus's phenomenology devolves into a conservative communitarianism that does not recognize 'the inevitability and vitality of social conflict.' (555). Whether or not this is true, it raises the issue of the political implications of Dreyfus's phenomenology. Dreyfus seems to have inherited Heidegger's positive valuation of the kind of knowledge that is involved in craft work. But did he also inherit Heidegger's conservatism or worse, his Nazism? Does a positive valuation of craft work or a tendency 
towards virtue ethics necessarily lead to conservatism? Is it communitarian, and then what kind of communitarianism? Is communitarianism necessarily conservative? Or are there other possibilities? And is there an unbridgeable gap between phenomenology and critical theory, or could Dreyfus's phenomenology be combined with some concerns and methods from critical theory?

Reading Dreyfus's work I do not see indications in the direction of conservatism, let alone Nazism, and I do not see why his thinking would necessarily lead into that direction. There is conservatism regarding technology, perhaps, but this does not necessarily imply social or political conservativism. However, these questions deserve further discussion, also in the light of contemporary debates about Heidegger's political sympathies. Since, as I have argued, Dreyfus's thinking has insufficiently engaged with the problem of the social, and since it has never been fully developed in terms of its social and political implications, it remains somewhat vulnerable to typical anti-Heideggerian criticisms. Therefore, if philosophers of technology want to use Dreyfus's thinking, they need to say more about the relations between skill and the social, and explicitly reflect on the normative and political directions this may take them. In the previous pages I have proposed some ways in which this can be done by staying relatively close to Dreyfus's own sources (rather than resorting to critical theory, for instance). In particular, I have suggested that using and combining Wittgenstein and Dewey (and maybe also MacIntyre) has a lot of potential to say more about the social in relation to the phenomenology of skillful coping.

More generally, more work is needed to develop these thoughts about how Wittgenstein, Dewey, and Dreyfus can be combined to (re)conceptualize and discuss virtue and its social dimension. This project requires, among other things, further engagement with Wittgenstein's work and its interpreters and a more elaborate discussion of both convergences and tensions between these thinkers. Here I have limited myself to offering some signposts in this direction, and to exploring some potential implications for philosophy of technology.

\section{Conclusion}

For thinking about technology, Dreyfus's account of skilled coping is and remains a valuable source, especially for those who are, like Dreyfus, interested in using Heidegger, Merleau-Ponty, and the later Wittgenstein to better understand the knowledge and experience involved in the use of tools, in skillful coping with and through technologies. However, I have also outlined and discussed some challenges that come with Dreyfus's approach: problems with regard to his assumptions about technology, his underdeveloped conceptions of the social dimension of skillful coping, and uncertainty with regard to the ethical and political implications of this view, including questions regarding the relation between virtue and skill. I have indicated some potential avenues for addressing these problems. In general, my recommendation to those inspired by Dreyfus in philosophy of technology is to take more distance from the later Heidegger's conception of technology and to do more with Wittgenstein and Dewey than Dreyfus did to deal with these challenges. I have indicated that there is also a lot of room for further development in the direction of virtue theory, for example by combining Dreyfus and Dewey or by engaging with the work of MacIntyre. Finally, so far authors working in the field of postphenomenology have not been very interested in Dreyfus's work (and vice versa); perhaps since the former rejects the latter as too Heideggerian. This neglect is to be regretted since Dreyfus's work, in particular its account of skillful coping, has a lot to offer to anyone interested in the phenomenology of technology use. By shifting the emphasis from the material artifact as such to its use and the skills and knowledge involved in that use, contemporary philosophers of technology in postphenomenology and related approaches could work towards a more relational and non-dualistic thinking about the relations between humans and technology — an aim Ihde may sympathize with.

More generally, Dreyfus's work constitutes a rich potential source of inspiration for philosophers of technology today, not only in the area of philosophy of AI but—with the account of skillful coping - also in other areas of thinking about technology. It is especially of interest to philosophers who aim to be sensitive to the phenomenology of living with technologies, to human experience with technologies. This attention to technology in the lifeworld also requires us to adopt, in contrast to Dreyfus and Heidegger, a view of new technologies that is more open and constructive and that goes beyond embodied tool use, without, however, dismissing the concerns about skill, alienation and virtue Dreyfus and others rightly raised. This could help philosophy of technology to further develop thinking about the phenomenological and ethical implications of AI: not in the abstract, but in use, as it is becoming part of our lifeworld and indeed of our skilled practices and our coping.

But Dreyfus's work also remains relevant to contemporary philosophy in general. Its main message is especially relevant and urgent when, and to the extent that, this philosophy is too mesmerized by formal and theoretical knowledge and by abstract arguments and principles, to the neglect of other, less explicit types of knowledge involved our everyday living and coping. Together with other key twentieth-century philosophers (and indeed contemporary cognitive science), Dreyfus successfully criticized the idea that we can separate mind and thinking from bodies and living people. If that were possible, we would not miss Dreyfus's voice here 
and now. The writings and other memory technologies we have would do the job of representing and preserving his thinking. But, as Dreyfus taught generations of philosophers by means of his teaching and (in my case) writings, neither thinking nor human beings can be reduced to what can be represented. Thinking needs to be embodied and lived. And, therefore-if not for other reasons-Hubert Dreyfus is greatly missed.

Acknowledgment Open access funding provided by University of Vienna.

Open Access This article is distributed under the terms of the Creative Commons Attribution 4.0 International License (http://creativeco mmons.org/licenses/by/4.0/), which permits unrestricted use, distribution, and reproduction in any medium, provided you give appropriate credit to the original author(s) and the source, provide a link to the Creative Commons license, and indicate if changes were made.

\section{References}

Andler D (2000) Context and background: Dreyfus and cognitive science. In: Wrathall M (ed) Heidegger, coping and cognitive science. MIT Press, Cambridge, pp 137-159

Annas J (1993) The morality of happiness. Oxford University Press, Oxford

Annas J (1995) Virtue as a skill. Int J Philos Stud 3(2):227-243. https ://doi.org/10.1080/09672559508570812

Annas J (2007) Virtue ethics. In: Copp D (ed) The Oxford handbook of ethical theory. Oxford University Press, Oxford

Borgmann A (1984) Technology and the character of contemporary life: a philosophical inquiry. The University of Chicago Press, Chicago

Breivik G (2007) Skillful coping in everyday life and in sport: a critical examination of the views of Heidegger and Dreyfus. J Philos Sport 34(2):116-134. https://doi.org/10.1080/00948705.2007.9714716

Carman T (2008) On being social: a reply to Olafson. Inquiry $37(2): 203-223$

Coeckelbergh M (2011a) Environmental virtue: motivation, skill, and (in)formation technology. J Environ Philos 8(2):141-170

Coeckelbergh M (2011b) Can we trust robots? Ethics Inf Technol 14:53-60

Coeckelbergh M (2012) Technology as skill and activity: revisiting the problem of alienation. Techné 16(3):208-230

Coeckelbergh M (2013a) Human being@ risk: enhancement, technology, and the evaluation of vulnerability transformations. Springer, Dordrecht

Coeckelbergh M (2013b) E-care as craftsmanship: virtuous work, skilled engagement, and information technology in health care. Med Healthc Philos 16(4):807-816

Coeckelbergh M (2014) Good healthcare is in the how: the quality of care, the role of machines, and the need for new skills. In: Coeckelbergh M, van Rysewyk SP, Pontier M (eds) Machine medical ethics. Springer, Berlin, pp 33-47

Coeckelbergh M (2015) Environmental skill: motivation, knowledge, and the possibility of a non-romantic environmental ethics. Routledge, New York

Coeckelbergh M (2016) Responsibility and the moral phenomenology of using self-driving cars. Appl Artif Intell 30(8):748-757
Coeckelbergh M (2017a) Using words and things: language and philosophy of technology. Routledge, New York

Coeckelbergh M (2017b) Technology games: using Wittgenstein for understanding and evaluating technology. Sci Eng Ethics https:// doi.org/10.1007/s11948-017-9953-8

Coeckelbergh M (2017c) Language and technology: maps, bridges, and pathways. AI Soc 32(2):175-189

Coeckelbergh M (2017d) New romantic cyborgs: romanticism, information technology, and the end of the machine. MIT Press, Cambridge

Coeckelbergh M, Funk M (2018) Wittgenstein as a philosopher of technology: tool use, forms of life, technique, and a transcendentalargument. Hum Stud https://doi.org/10.1007/s1074 6-017-9452-6(online first)

Collins H (1992) Hubert L. Dreyfus, forms of life, and a simple test for machine intelligence. Soc Stud Sci 22:726-739. http://www. jstor.org/stable/285462

Collins H (2013) The core of expertise. Phenomenol Cognit Sci 12:399-416. https://doi.org/10.1007/s11097-012-9277-8

Crawford MB (2009) Shop class as soulcraft: an inquiry into the value of work. Penguin Press, New York

Dewey J (1922) Human nature and conduct. Allen \& Unwin, London

Dewey J (1929) Experience and nature. George Allen \& Unwin, London

Dreyfus HL (1967) Why computers must have bodies in order to be intelligent. Rev Metaphys 21(1):13-32

Dreyfus HL (1972) What computers can't do. the limits of artificial intelligence. MIT Press, New York

Dreyfus HL (1975) The priority of the world to my world: Heidegger's answer to Husserl (and Sartre). Man World 8:121-130

Dreyfus HL (1980b) Holism and hermeneutics. Rev Metaphys $34(1): 3-23$

Dreyfus HL (1991) Towards a phenomenology of ethical expertise. Hum Stud 14:229-250

Dreyfus HL (1992) Response to Collins, artificial experts. Soc Stud Sci 22(4):717-726

Dreyfus HL (1999) The primacy of phenomenology over logical analysis. Philos Top 27(2):3-24

Dreyfus HL (2001a) Phenomenological description versus rational reconstruction. Rev Int Philos 2(216):181-196

Dreyfus HL (2001b) On the internet (revised 2nd edition), 2009. Routledge, London

Dreyfus HL (2002a) Intelligence without representation-MerleauPonty's critique of mental representation. Phenomenol Cognit Sci 1:367-383. https://doi.org/10.1023/A:1021351606209

Dreyfus HL (2002b) Refocusing the question: can there be skillful coping without propositional representations or brain representations? Phenomenol Cognit Sci 1:413-425

Dreyfus HL (2005) Overcoming the myth of the mental: how philosophers can profit from the phenomenon of everyday expertise. Proc Addresses Am Philos Assoc 79(2):pp 47-65

Dreyfus HL (2007a) The return of the myth of the mental. Inquiry 50(4):352-365. https://doi.org/10.1080/00201740701489245

Dreyfus HL (2007b) Response to McDowell. Inquiry 50(4):371-377. https://doi.org/10.1080/00201740701489401

Dreyfus HL (2012) Introductory essay: the mystery of the background qua background. In: Radman Z (ed) Knowing without thinking. Palgrave Macmillan, Basingstoke, pp 1-10

Dreyfus HL (2014) Skillful coping: essays on the phenomenology of everyday perception and action. In: Wrathall M (ed) Oxford University Press, Oxford

Dreyfus S, Dreyfus HL (1980a) A five-stage model of the mental activities involved in directed skill acquisition. Operations Research Centre, University of California, Berkeley

Dreyfus HL, Kelly SE (2011) All things shining. Reading theWestern classics to find meaning in a secular age. Free Press, New York 
Heidegger M (1927) Being and time: a translation of Sein und Zeit, Stambaugh J (trans, 1996). State University of New York, Albany

Heidegger M (1977) The question concerning technology. In: Lovitt W (trans) The question concerning technology and other essays. Harper \& Row, New York, pp 3-35

Ihde D (1990) Technology and the lifeworld: from garden to earth. Indiana University Press, Bloomington

MacIntyre A (1984) After virtue: a study in moral theory, 3rd edn. 2007. University of Notre Dame Press, Notre Dame

McDowell J (2007) Response to Dreyfus. Inquiry 50(4):366-370. https ://doi.org/10.1080/00201740701489351

McManus D (2007) Rules, regression and the 'Background': Dreyfus, Heidegger and McDowell. Eur J Philos 16(3):432-458. https:// doi.org/10.1111/j.1468-0378.2007.00255.x

McPherson I (2005) Reflexive learning: stages towards wisdom with Dreyfus. Educ Philos Theory 37(5):705-718. https://doi.org/10. 1111/j.1469-5812.2005.00152.x

Merleau-Ponty M (1945) Phenomenology of perception. Smith C (trans, 1962). Routledge, New York

Olafson FA (2008) Heidegger à la Wittgenstein or 'coping' with Professor Dreyfus. Inquiry 37(1):45-64

Reynolds J (2006) Dreyfus and deleuze on, coping, and trauma in skill acquisition. Int J Philos Stud 14(4):539-559
Rietveld E (2010) McDowell and Dreyfus on unreflective action. Inquiry 53(2):183-207. https://doi.org/10.1080/0020174100 3612203

Selinger E, Crease RP (2003) Dreyfus on expertise: the limits of phenomenological analysis. Cont Philos Rev 35:245-279

Stichter M (2007) Ethical expertise: the skill model of virtue. Ethical Theory Moral Pract 10:183-194. http://www.jstor.org/stabl e/40602522

Vallor S (2015) Moral deskilling and upskilling in a new machine age: reflections on the ambiguous future of character. Philos Technol 28:107-124

Vallor S (2016) Technology and the virtues: a philosophical guide to a future worth wanting. Oxford University Press, New York

Verbeek P (2005) What things do: philosophical reflections on technology, agency, and design. The Pennsylvania State University Press, University Park

Winner L (1986) The whale and the reactor: a search for limits in an age of high technology. The University of Chicago Press, Chicago

Wittgenstein L (1969) On Certainty. In: Anscombe GEM, von Wright GH (eds) Basil Blackwell, Oxford(trans: Paul D, Anscombe GEM)

Wittgenstein L,. (trans: Anscombe E, Hacker PMS, Schulte J (1953/2009) Philosophical investigations, 4th edn. Wiley-Blackwell, Malden 